\title{
Discovery of Chlorogenic Acid-Based Peptidomimetics as a Novel Class of Antifungals. A Success Story in Rational Drug Design
}

\author{
Mohsen Daneshtalab \\ School of Pharmacy, Memorial University of Newfoundland, St. John's, Canada. \\ Received, June 6, 2008; Revised, July 2, 2008; Accepted, July 2, 2008; Published, July 3, 2008.
}

\begin{abstract}
Life-threatening fungal infections have increased dramatically in recent decades in immunocompromised patients. An estimated 40\% of all deaths from hospital-acquired infections are due to infections caused by opportunistic fungi. The current treatment options are either causing serious toxicity, or becoming inactive against the drugresistant fungal strains. Thus, the discovery and development of new antifungal agents that are economically feasible, have excellent therapeutic value, and address the problems of toxicity and species resistance is very important. We have recently designed and synthesized a series of chlorogenic acid-based peptidimimetics using structure-based methodology starting with cyclic peptides of the candin class of antifungals. These novel and totally synthetic compounds exhibit promising antifungal activity against pathogenic fungi with very low toxicity against brine shrimps. The possible novelty in their mechanism of action and economically feasible synthetic approach are the attractive features of this class of compounds that make them different from the already utilized antifungal agents.
\end{abstract}

\section{INTRODUCTION}

Life-threatening fungal infections have increased dramatically in recent decades in immunocompromised patients such as those undergoing cancer chemotherapy, organ transplant, and patients with AIDS (1-4). Candida spp. (including albicans and non-albicans) have been the major opportunistic pathogens $(2,5,6)$. Aspergillus fumigatus (the causative pathogen in invasive pulmonary aspergillosis) is the leading factor of mortality in bone-marrow transplant recipients (7), while HIV-infected patients are particularly susceptible to mucosal candidiasis, cryptococcal meningitis, disseminated histoplasmosis, coccidioidomycosis, and Pneumocystis carinii pneumonia (8-10).

Treatment of systemic and invasive fungal infections is a major challenge in immunocompromised patients. Amphotericin B is still the gold standard for the treatment of most severe invasive fungal infections. However, it exhibits acute and chronic side effects, which may be reduced by newer formulations within liposomes (11), lipid complexes (12), and colloidal dispersions $(13,14)$. Azole antifungals including fluconazole, itraconazole, and the recently introduced posaconazole, are totally synthetic compounds with broad fungistatic activity against most yeasts and filamentous fungi. Despite being free of serious toxicity, they may produce endocrine-related side effects such as depletion of testosterone and glucocorticoids, resulting in gynecomastia and adrenal insufficiency $(15,16)$. Another major limitation in the application of azoles, especially fluconazole, is the emergence of resistant fungal strains including Candida spp. (albicans and nonalbicans) $(17,18)$, and Cryptococcus neoformans (19).

Since late 1970, inhibitors of 1,3- $\beta$-glucan synthase, the enzyme involved in the formation of $1,3-\beta$-glucan, one of the main components of the fungal cell wall, have gained worldwide popularity as potential drugs for the treatment of systemic and invasive mycoses. These compounds, which are mainly natural products or their semisynthetic analogues, have been classified as lipopolysaccharides, such as papulacandins, lipoproteins, such as echinocandins (20), and acidic terpenoids such as enfumafungin (21).

Corresponding Author: Mohsen Daneshtalab, School of Pharmacy, Memorial University of Newfoundland, St. John's, Canada,Email: mohsen@mun.ca 
Papulacandins are no longer being utilized as antifungal agents since their antifungal activity is limited to Candida species and, most importantly, their in vitro activity does not translate to in vivo activity (22). Echinocandins on the other hand exhibit strong fungicidal activity in both in vitro and in vivo animal models $(23,24)$. Echinocandins have been chemically modified to produce semisynthetic analogues with improved pharmacological properties. Among the structurally modified compounds in cyclic hexapeptide series, two semisynthetic derivatives, LY-303,366 (anidulafungin) of echinocandin $\mathrm{B}$ class $(25,26)$ and L-733,560 of pneumocandin $\mathrm{B}_{0}$ class $(27,28)$ have exhibited extremely promising in vitro and in vivo activities against Candida species, $P$. carinii, and other pathogenic fungi. Recently, a new pneumocandin $\mathrm{B}_{0}$ analogue, L-743,872 (MK-0991, caspofungin) and its analogue Micafungin (FK-463) have been approved for the treatment of lifethreatening fungal infections (29-31). The structures of the above 1,3- $\beta$-glucan synthase inhibitors are illustrated in Figure-1.

Considering the mode of action, pharmacological, and toxicological profiles of the above classes of compounds (amphotericin B, disruption of fungal cell wall function; azoles, inhibition of fungal cell-membrane formation via inhibition of $\mathrm{CYP}_{450}$-dependent lanosterol 14- $\alpha$ demethylase; and candin class of compounds, inhibition of fungal cell wall formation via inhibition of $1,3-\beta$-glucan synthase), the candin class of antifungals exhibit the most promising target selectivity, as $1,3-\beta$-glucan is only found in fungi not in mammalian cells. This imminently results in less physiologically toxic effects, as compared to the other two classes. Moreover, the semi-synthetically modified candins have rarely shown fungal resistance selection and are freely water soluble, the properties which are attractive for any clinically utilized antifungal drug. Despite the advantages in hand, the candin class of compounds has its own limitations as well. Firstly, due to their semi-synthetic nature, they are costly (29). Secondly, none of these compounds exhibit activity against Cryptococcus neoformans which is the causative agent for cryptococcal meningitis in AIDS patients, and is the major cause of opportunistic fungal mortality in these patients (23,
24). This difference is due to selectivity of candin class of compounds against 1,3 - $\beta$-glucan synthase which does not exist in $C$. neoformans, as the glucan structure of this fungus consists of $1,6-\beta$ glucan rather than $1,3-\beta$-glucan, and is formed by the catalytic action of $1,6-\beta$-glucan synthase (22, 32 ). Finally, these compounds are only available as injectable forms due to their poor oral bioavailability. Considering the advantages and limitations of candin class of compounds, our group attempted the design and synthesis of peptidomimetic analogues of echinocandin B using structure-based methodology and HyperChem ${ }^{\mathrm{TM}}$ program.

\section{RATIONALE}

The enzyme 1,3- $\beta$-glucan synthase has at least two functional components: a catalytic component, which acts on UDP-glucose substrate, and a regulatory component, which binds to GTP (33, 34). Considering the possible interaction of echinocandins (hexapeptides with symmetric structures consisting dipeptidic backbones of hydroxyproline-threonine at their south-eastern and north-western parts of the molecule) with the catalytic component of the enzyme and, as a result, inhibition of enzymatic activity, we attempted to design linear as well as cyclic peptidomimetic molecules that would possibly mimic the dipeptidic backbone of echinocandins. Using HyperChem ${ }^{\mathrm{TM}}$ program, we designed and synthesized representative compounds I and II (linear) and III and IV (cyclic) peptidomimetics and evaluated them for antifungal activity (Figures 2 and 3a,b) (35).

The cell-based antifungal activity and 1,3$\beta$-glucan inhibitory evaluations of these new peptidomimetics revealed that none of these compounds were active. These results were in agreement with the general structural requirement for the enzyme inhibitory/antifungal activity of echinocandin class of compounds as described by Zambias et. al., and Taft et. al. (36, 37). Namely, the echinocandin lipophilic side chain at the northern part of the structure, and the homotyrosine moiety at the southern part, alongside the dipeptidic hydroxyproline-threonine, are the essential groups for the activity of echinocandin series. 


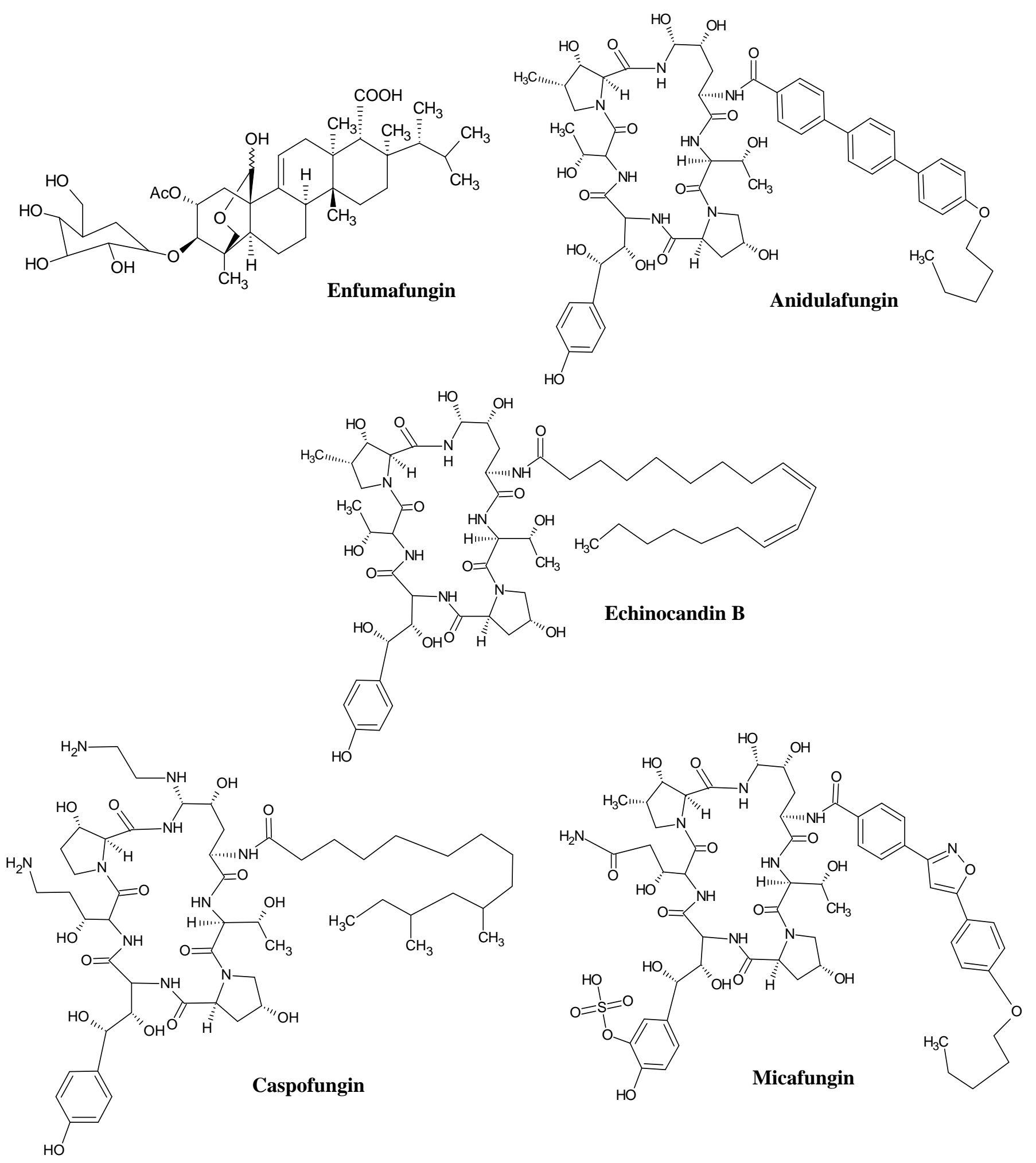

Figure 1. Structures of conventional 1,3- $\beta$-glucan synthase inhibitors. 


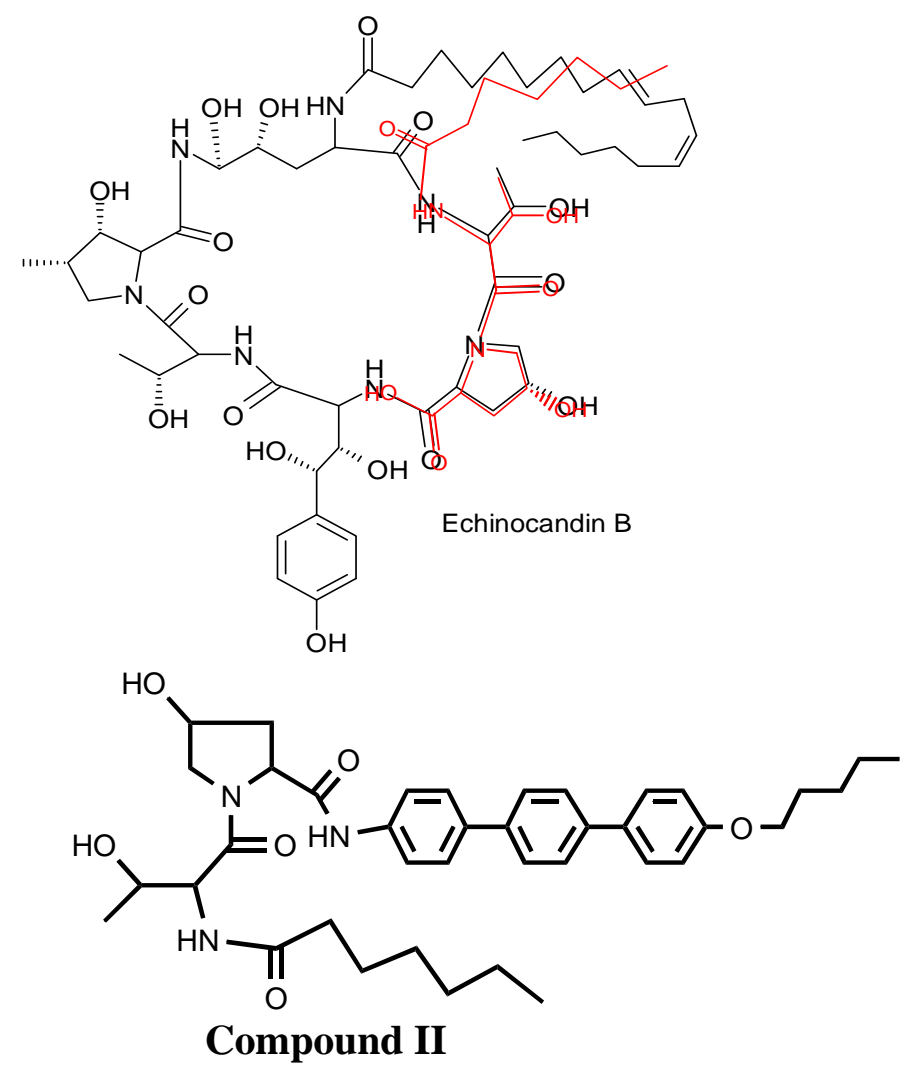

Figure 2. Overlay of Echinocandin B with Compound I (red) and structure of Compound II.

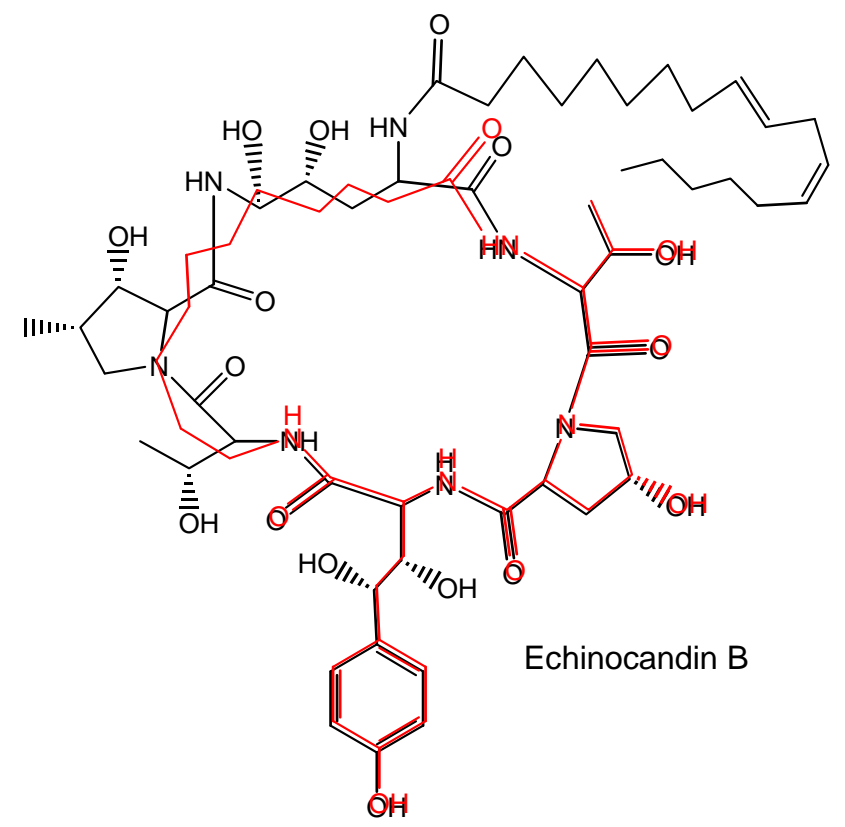

Figure 3a. Overlay of compound III (red) with echinocandin B. 


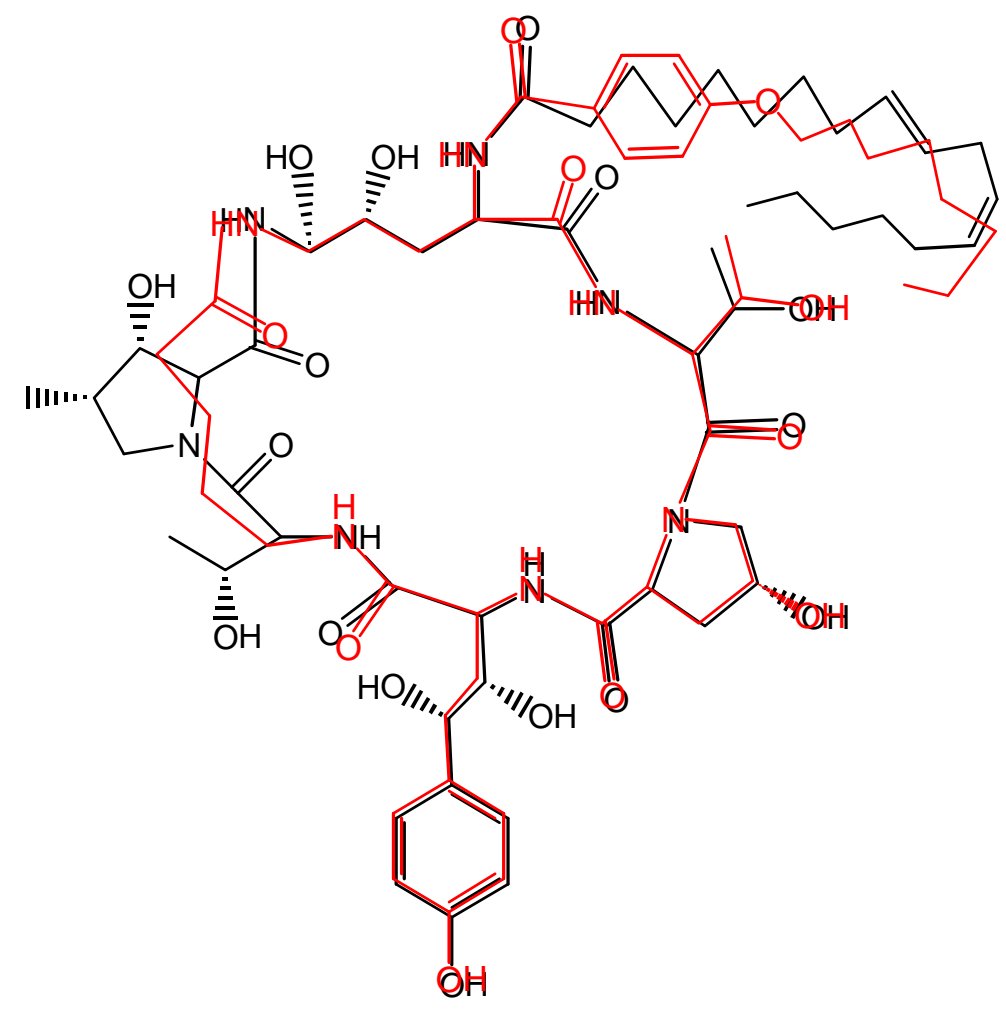

Figure 3b. Overlay of compound IV (red) with echinocandin B.

Also the orientation of homotyrosine ring with respect to the lipophilic side chain may be the determining factor for the antifungal activity of this class of compounds (Figure 4).

Chlorogenic acid is a natural product existing widely in many vegetables and plants. Structurally, it is a caffeoyl ester of quinic acid (Figure 5). Derivatives of chlorogenic acid have been reported to have interesting bioactivity such as inhibitory activity on HIV integrase (38) and protease (39). Chlorogenic acid can be considered a bioisostere of homotyrosine-hydroxyproline / theronine component located at the southern and south-eastern parts of echinocandin B.

Based on the above documentations and considering bioisosterism, a molecule such as chlorogenic acid would be an ideal bioiososteric replacement for the homo-tyrosine-hydroxyproline / threonine (southern and south-eastern parts of echinocandin B) when coupled with a lipophilic side chain, which may result in formation of a series of novel and potential bioactive antifungal molecules.
Considering the above facts, we hypothesized that the coupling of chlorogenic acid with appropriate lipophilic groups should result in compounds that are able to mimic the structural feature of homotyrosine-hydroxyproline/theroninelipophilic moieties, required for 1,3- $\beta$-glucan synthase inhibitory/antifungal activity of echinocandin class of compounds. In order to prove this hypothesis, 3-dimensional models of the energetically/stereochemically minimized echinocandin $\mathrm{B}$, chlorogenic acid, and chlorogenic acid coupled with octyloxyaniline were established using HyperChem ${ }^{\mathrm{TM}}$ software. The 3 - points overlay of chlorogenic acid/echinocandin (Figure 6) and chlorogenic acid - coupled - octyloxyanilide / echinocandin (Figure 7) were determined.

Indeed, the overlay matching of chlorogenic acid and its octyloxyanilide with echinocandin derivative was confirmed, as shown in Figures 6 and 7, which led us to design and synthesize different chlorogenic acid-based peptidomimetics with potential antifungal properties that are structurally novel. 


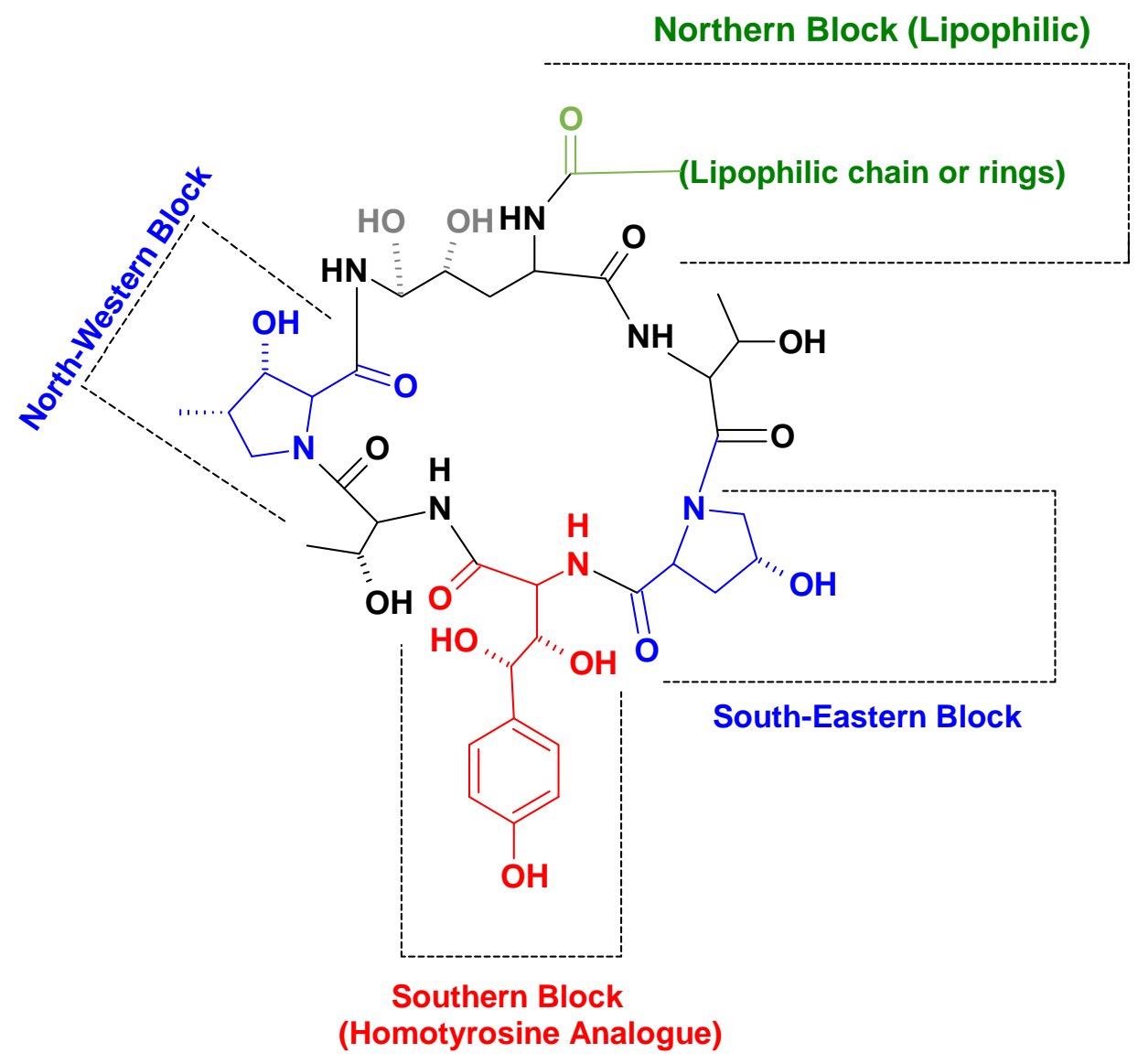

Figure 4. Structural requirement for the interaction of echinocandins with 1,3-beta-glucan synthase.

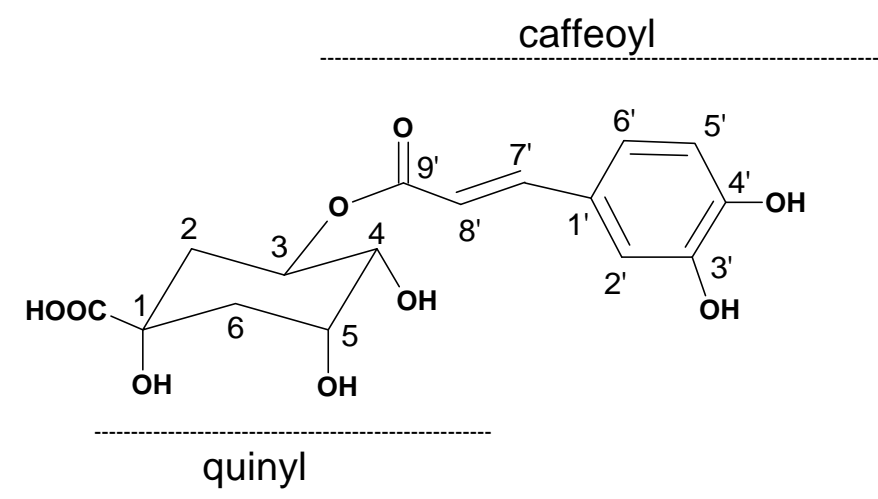

Figure 5. Structure of chlorogenic acid. 


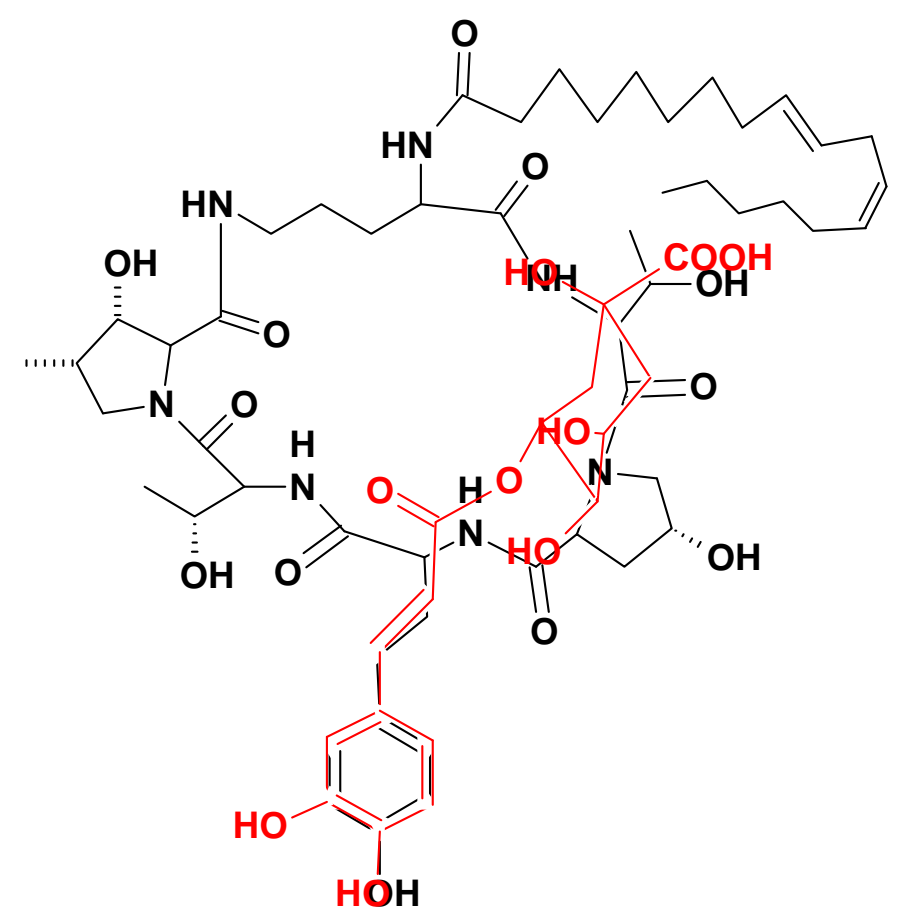

Figure 6. Overlay of chlorogenic acid with echinocandin derivative.

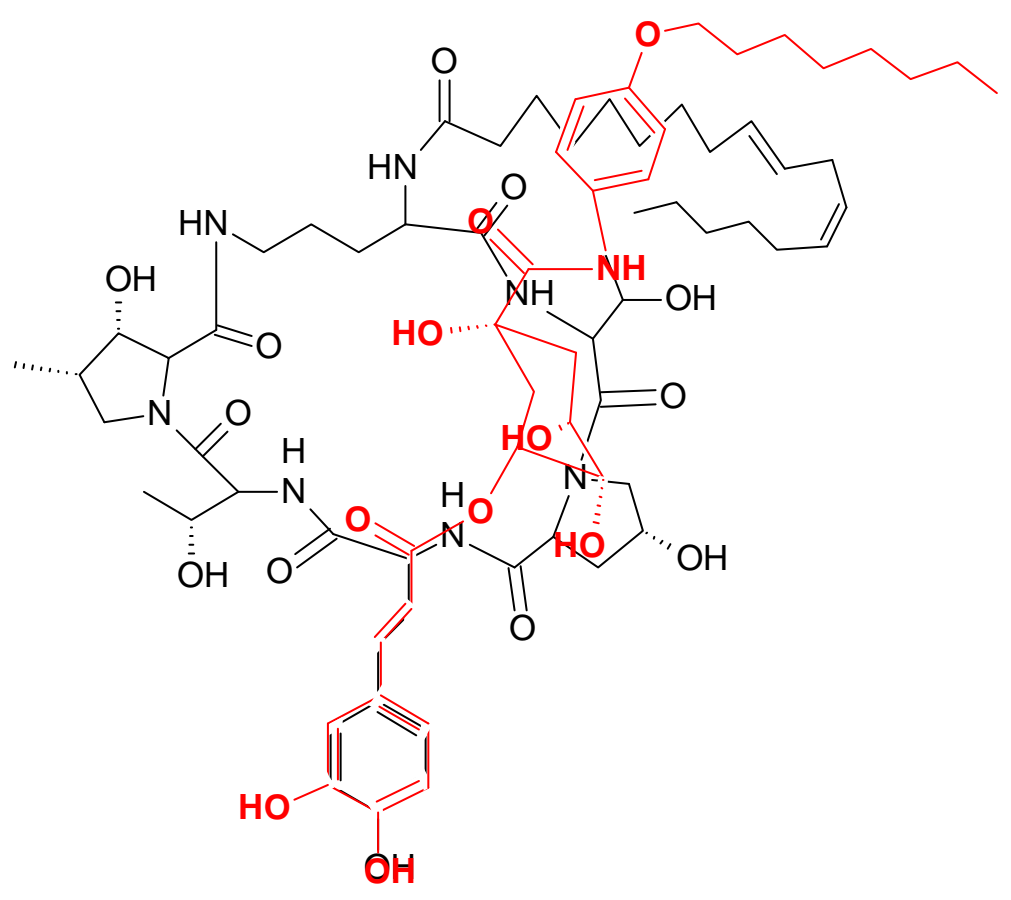

Figure 7. Overlay of chlorogenic acid p-(octyloxy)anilide with echinocandin derivative. 


\section{CHEMISTRY AND STRUCTURE-ACTIVITY RELATIONSHIPS}

The synthesis of these chlorogenic acid derivatives was reported previously (40) and is depicted in Scheme 1. Namely, the diacetonide derivative of chlorogenic acid was condensed with 4(octyloxy)aniline to obtain the corresponding amide intermediate which upon deprotection yielded compound 1. Both compound $\mathbf{1}$ and its diacetonide analogue showed reasonable antifungal activity. To investigate the influence of physicochemical properties on antifungal activity, selected amino acids were introduced into the structures. For the synthesis of these compounds, protected amino acid derivatives were condensed with 4 - (octyloxy) aniline to obtain the corresponding protected amides with a lipophilic side-chain (2). Deprotection of these compounds under $\mathrm{NHEt}_{2}$ followed by their reaction with the acetonide of chlorogenic acid afforded the corresponding protected amides (3). Acid hydrolyses of these protected acetonides under controlled condition resulted in the formation of the corresponding amine-protected derivatives, which upon further deprotection using 90\% TFA yielded the desired peptidomimetics of chlorogenic acid (4).

To further investigate the SAR among this class of compounds, the corresponding dihydro derivatives (5) and monohydroxyphenyls (6) were also synthesized and tested for antifungal activity and toxicity (M. Daneshtalab, unpublished data).

The synthesized compounds were evaluated for in vitro antifungal activity against Candida albicans ATCC90028, Cryptococcus neoformans ATCC32045 and Aspergillus fumigatus ATCC13073, and toxicity using "brine-shrimp lethality assay, " and the results were reported previously (40). Overall, chlorogenic acid derivatives (3 and 4) exhibited better antifungal activity or less toxicity than those of chlorogenic acid analogues (5 and 6). This suggests that the structural modification on the caffeoyl group, such as saturating the double bond or reducing the number of hydroxyl groups results in reduction of antifungal activity. Significant antifungal activity was observed in most of the chlorogenic acid derivatives (3 and 4). The MIC on Cryptococcus neoformans of nearly all these chlorogenic acid derivatives were as low as $1-4 \mu \mathrm{g} / \mathrm{ml}$, except the compound possessing a free carboxylic acid group in its structure which had MIC of $16 \mu \mathrm{g} / \mathrm{ml}$. It has been reported that incorporation of an amino group, such as aminoproline residue, into the ring of echinocadin analogues leads to improvement of antifungal potency (41). Similar effects were observed in the chlorogenic acid derivatives that are reported here. Namely, compound 4d with a free amino group in its structure showed good activity against all the fungi tested, including $A$. Fumigatus (MIC of $16 \mu \mathrm{g} / \mathrm{ml}$ ). The MIC of the chlorogenic acid derivatives against $C$. Albicans varied from 2 to $>64 \mu \mathrm{g} / \mathrm{ml}$. All the acetonide compounds showed weaker inhibitory activity against $C$. Albicans than the corresponding compounds with free hydroxyl groups, suggesting that the two hydroxyl groups in the quinic acid part are essential for the activity.

The general toxicity of these compounds was assessed using brine shrimp lethality assay according to the reported method (42) and is reported in detail in our previous paper (40). Most of the synthesized compounds exhibited moderate to very low toxicity against brine shrimp.

Based on the selective activity of these compounds against Cryptococcus neoformans, weak activity against Candida albicans, and very weak or no activity against Aspergillus fumigatus, we hypothesize that these compounds may have selective inhibitory activity against 1,6- $\beta$-glucan synthase (which is mainly found in $C$. neoformans and partially in Candida species). Other possible mechanism is increasing the permeability of fungal cell wall via mimicking the action of bactericidal/permeability-increasing protein, a mechanism that has been reported for antifungal activity of some peptides that are structurally related to chlorogenic acid (43).

\section{CONCLUSION}

A systematic structural modification of the cyclic peptides of candin class of antifunfgals resulted in identification of a novel class of small molecule chlorogenic acid-based peptidomimetics with impressive antifungal/toxicity profile and short synthetic steps. 


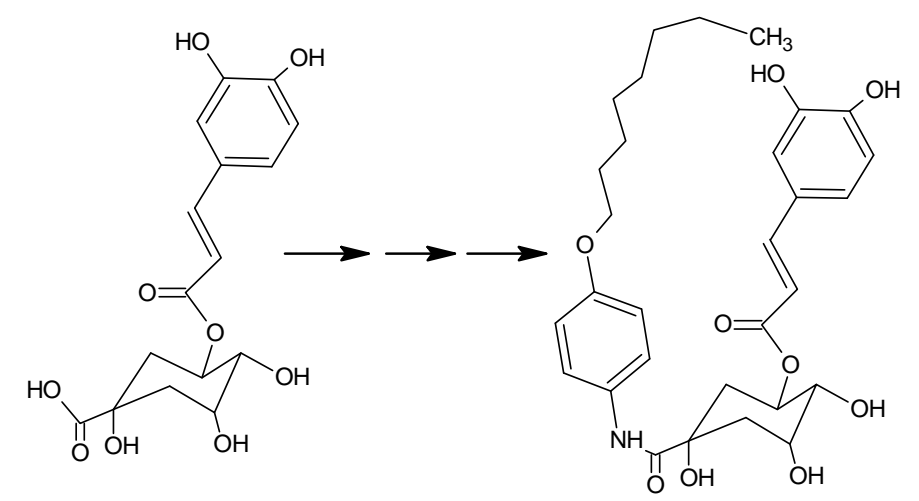

(1)

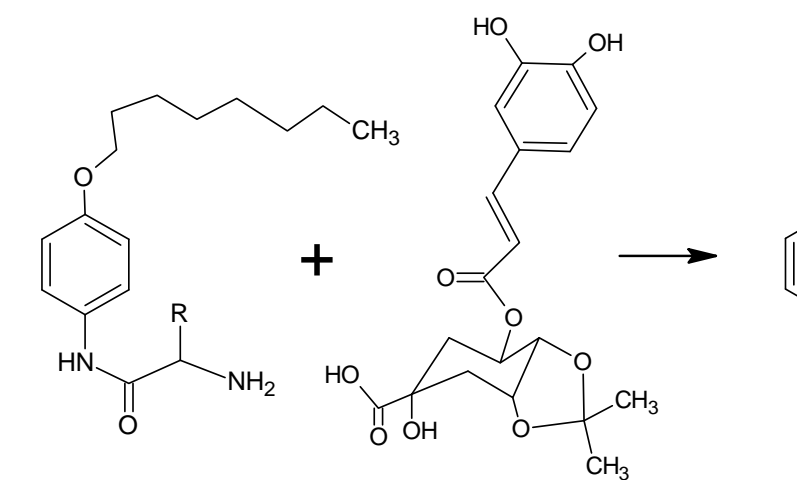

( 2 )

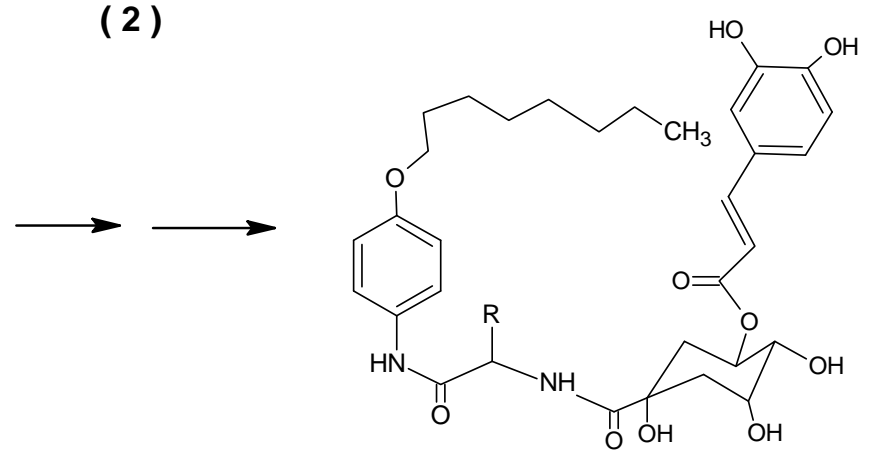

( 3 )<smiles>[R]C(NC(=O)C1CC2OC(C)(C)OC1C2OC(=O)/C=C/c1ccc(O)c(O)c1)C(=O)Nc1ccc(OCCCCCCCC)cc1</smiles>

$$
\begin{aligned}
\mathrm{R} & =-\mathrm{CH}_{2} \mathrm{OH} \text { (a) } \\
& =-\mathrm{CH}\left(\mathrm{CH}_{3}\right)-\mathrm{OH} \text { (b) } \\
& =-\mathrm{CH}_{2} \mathrm{COOH} \text { (c) } \\
& =-\left(\mathrm{CH}_{2}\right)_{3} \mathrm{NH}_{2} \text { (d) }
\end{aligned}
$$

(4)

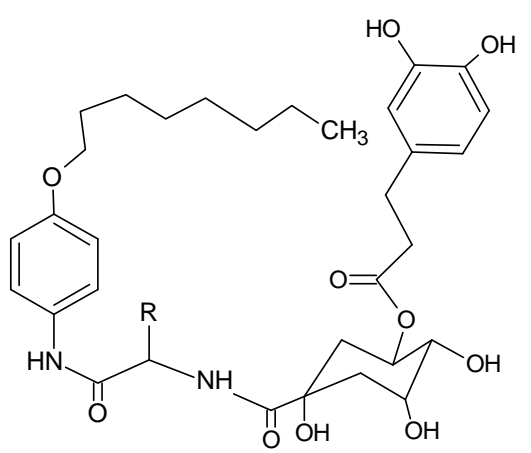

( 5 )

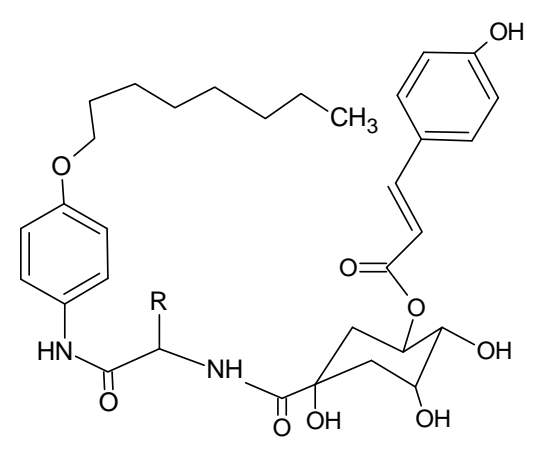

(6)

Scheme 1. General syntheses of peptidomimetic chlorogenic acid derivatives 
Based on the in vitro activity / toxicity profile, compound 4a has been selected as the lead compound for further structural modifications. We expect that a sequential structural modification on compound 4d through changing the amino acid components that are coupled with the quinic acid part of chlorogenic acid, the lipophilic side chain (octyloxyaniline), and the quinic acid moiety may lead to discovery of a preclinical lead compound with optimum activity/toxicity profile.

The results obtained in our preliminary investigation on this novel class of compounds strongly confirm their potential as new leads for the discovery and development of novel mechanism based antifungal agents.

\section{REFERENCES}

[1]. Anaissie, E.J. Opportunistic mycoses in immunocompromised host: Experience at a cancer center and review. Clin. Infect. Dis., 14 (suupl. 1), 43-53, 1992.

[2]. Richardson, M.D. Opportunistic and pathogenic fungi. J. Antimicrob. Chemother., 28 (Suppl. A), 1-11, 1991.

[3]. Pfaller, M.A., Wenzel R. The impact of changing epidemiology of fungal infections in the 1990s. Eur. J. Clin. Microbiol. Infect. Dis., 11, 287-291, 1992.

[4]. Georgopapadakou, N.H., Walsh T.J. Antifungal agents: chemotherapeutic targets and immunologic Strategies. Antimicrob. Agents Chemother., 40, 279-291, 1996.

[5]. Beck-Sague, C.M., Jarvis, W.R. Secular trends in the epidemiology of nosocomial fungal infections in the United States. 1980-1990. J. infect. Dis., 167, 1247-1251, 1993.

[6]. Walsh, T.J., Pizzo, P.A. Nosocomial fungal infections. Ann. Rev. Microbiol., 42, 517- 545, 1998.

[7]. Pannuti, C.S., Gingrich, R., Pfaller, M.A., Kao, C., Wenzel, R.P. Nosocomial pneumonia in patients having bone marrow transplant. Cancer, 69, 2653-2662, 1992.

[8]. Diamond, R.D. The growing problem of mycoses in patients infected with the human immunodefficeincy virus. Rev. Infect. Dis., 13, 480-486, 1991.

[9]. Ample, N.M., Dols, C.L., Galgiani, J.N. Coccidioidomycosis during human immunodeficiency virus infection: results of a prospective study in coccidioidal endemic area. Am. J. Med., 94, 235-240, 1993.
[10]. Hughes, W.T. Pneumocystis carinii pneumonia: new approaches to diagnosis, treatment and prevention. Pediatr. Infect. Dis. J., 10, 391-399, 1991.

[11]. Alder-Moore, J.P., Proffitt, R. T. Development, characterization, efficacy and mode of action of AmBisome, a unilammellar liposomal formulation of amphotericin B. J. Liposoaml Res., 3, 429-450, 1993.

[12]. Meunier, F. New methods for delivery of antifungal agents. Rev. Infect. Dis., 11 (suppl. 7), 1605-1609, 1989.

[13]. Patterson, T.F., Miniter, P., Dijkstra, J, Szoka, Jr., F.C., Ryan, J.L., Andriole, V.T. Treatment of experimental invasive aspergillosis with novel amphotericin B cholesterol sulfate complex. J. Infect. Dis., 159, 717-724, 1989.

[14]. Hanson, L.H., Stevens, D.A. Comparison of the antifungal activity of amphotericin B deoxycholate suspension with that of amphotericin cholestryl sulfate colloidal dispersion. Antimicrob. Agents Chemother., 36, 486-488, 1992.

[15]. Bartlett-Bee, K., Lees, J., Pinder, P., , Campbell, J., Newboult, L. Biochemical studies with a model antifungal agent. ICI 195,739. Ann. N. Y. Acad. Sci., 544, 231-244, 1988.

[16]. Hanger, D.P., Jevons, S., Shaw, J.T.B. Fluconazole and testosterone: in vivo and in vitro studies. Antimicrob Agents Chemother., 32, 646648, 1988.

[17]. Johnson, E.M., Warnock, D.W., Luker, J., Porter, S.R., Scully, C. Emergence of azole drug resistance in Candida species from HIV-infected patients receiving prolonged fluconazole therapy for oral candidosis. J. Antimicrob. Chemother., 35, 103-114, 1995.

[18]. Rex, J.H., Rinaldi, M.G., Pfaller, M.A. Resistance of candida species to fluconazole. Antimicrob. Agents Chemother., 39, 1-8, 1995.

[19]. Coker, R.J., Harris, J.R.W. Failure of fluconazole treatment in cryptococcal meningitis despite adequate SCF levels. I. Infect., 23, 101103, 1991.

[20]. Tkacz, J.S. Glucan biosynthesis in fungi and its inhibition. In Sutcliffe, J., and Georgopapadaku, N.H. (ed.), Emerging targets in antibacterial and antifungal chemotherapy. Chapman \& Hall, New York, p. 495-523, 1992.

[21]. Onishi, J., Meinz, M., Curotto, J., Dreikorn, S., Rosenbach, M., Douglas, C., Abruzzo, G., Flattery, A., Kong, L., Cabello, A., Vicente, F., Pelaez, F., Diez, M.T., Martin, I., Bills, G.Giacobbe, R., Dombrowski, A., Schwartz, R., Morris, S., Harris, G., Tsipouras, A., Wilson, K., and Kurtz, M.B. Discovery of Novel Antifungal 
$(1,3)-\beta$-D-Glucan Synthase Inhibitors. Antimicrob. Agents Chemother., 44, 368-377, 2000.

[22]. Georgopapadaku, N.H., Tkacz, J.S. The fungal cell wall as a drug target. Trends Microbiol. 3, 98-104, 1995.

[23]. Walsh, T. J. Invasive fungal infections: problems and challenges in developing new antifungal compounds. In Sutcliffe, J., and Georgopapadaku, N.H. (ed.), Emerging targets in antibacterial and antifungal chemo therapy. Chapman \& Hall, New York, p. 349-373, 1992.

[24]. Walsh, T.J., Lee, J.W., Kelly, P., Bacher, J., Lecciones, J., Thomas, V., Lyman, C., Coleman, D., Godee, R., Pizzo, P.A. The antifungal effects of the nonlinear pharmacokinetics of cilofungin, a 1,3- $\beta$-glucan synthase inhibitor, during continuous vs. intermittent infusion of cilofungin in the treatment of experimental disseminated candidiasis. Antimicrtob. Agents Chemother., 35, 1321-1328, 1991.

[25]. Current, W.L., Boylan, C.J., Zeckner, D., Raab, P., Butler, T., Gordee, R.S., Farmer, J., Turner, W.W., Burkhardt, F.J., Debono, M., LaGrandeur, L.M., Rodriguez, M., Zweifel, M., Startford, R., Zornes, L., Petersen, B., Green, L., Steimel, L., Novilla, M.N., Beaulieu, D., Tang, J., Paar, T. LY303366, a new semi-synthetic lipopeptide agent related to Echinocandin B: activity and efficacy against pathogenic fungi, including Pneumocystiscarinii. In Lili Satellite Symposium, $18^{\text {th }}$ International Congress of Chemotherapy, p. 18-20, 1993

[26]. Cada, D.J., Levien, T. Anidulafungin. Hospital Pharmacy, 41, 669-680, 2006.

[27]. Bouffard, F.A., Zambias, R.A., Dropinski, J.F., Balkovec J.M., Hammond, M.L., Abruzzo, G.K., Bartizal, K.F., Marrinan, J.A., Kurtz, M.B., McFadden, D.C., Nollstadt, K.H., Powels, M.A., Schmatz, D.M. Synthesis and antifungal activity of novel cationic pneumocandin $\mathrm{B}_{0}$ derivatives. J. Med. Chem., 37, 222-224, 1994.

[28]. Schmatz, D., Romanchek, M, Pittarelli, L., Schwartz, R., Formtling, R., Nollstadt, K., VanMiddlesworth, F., Wilson, K., Turner, M. Treatment of Pneumocystis carinii pneumonia with 1,3- $\beta$-glucan synthase inhibitors. Proc. Nat. Acad. Sci. USA, 87, 5450-5954, 1990.

[29]. Bouffard F.A., Dropinski, J.F., Balkovec J.M., Black, R.M., Hammond, M.L., Nollstadt, K.H., DreikornS. L-743,872, a Novel Antifungal Lipopeptide: Synthesis and Structure-Activity Relationships of New Aza-Substituted Pneumocandins. The $36^{\text {th }}$ ICAAC Meetings, New Orleans, LA, Sept. 1996. Abstr. No. F 27, p. $15-18$.
[30]. Rybowicz, J., Gurk-Turner, C. Caspofungin: The first agent available in the echinocandin class of antifungals. Baylor University Medical Center Proceedings, 15, 97-99, 2002.

[31]. Fujie, A. Discovery of micafungim (FK463): A novel antifungal drug derived from Natural product lead. Pure Appl. Chem, 79, 603-614, 2007.

[32]. Hartland, R.P., Emerson, G.W., Sullivan, P.A. A secreted $\beta$-glucan-branching enzyme from Candida albicans. Proc. R. Soc. London Ser. B. Biol. Sci. 246, 155-160, 1991.

[33]. Cabib, E., Kang, M.S. Fungal 1,3- $\beta$-glucan synthase. Methods Enzymol. 138, 637-642, 1987.

[34]. Mol, P.C., Park, H.-M., Mullins, J.T., Cabib, E. A GTP-binding protein regulates the activity of $1,3-\beta$-glucan synthase, an enzyme directly involved in yeast cell wall morphogenesis. J. Biol. Chem., 296, 31267-31274, 1994.

[35]. Ma, C., Takeda, S., Hibino, S., Daneshtalab, M. Synthesis of Peptidomimetic Analogues of Echinocandins. Heterocycles, 68, 721-732, 2006.

[36]. Zambias, R.A., Hammond, M.L., Heck, J.V., Bartizal, K., Trainor, C., Arbuzzo, G., Schmatz, D.M., Nollstadt, K.M. Preparation and StructureActivity Relationships of Simplified Aanlogues of Antifungal Agent Cilofungin: A Total Synthesis Approach. J. Med. Chem., 35, 28432855, 1992.

[37]. Taft, C.S., Selitrennikoff, C.P. Cilofungin inhibition of $(1,3)-\beta$-glucan synthase: the lipophilic side chain is essential for inhibition of enzyme activity. J. Antibiot., 43, 433-437, 1990.

[38]. Robinson, W. E. Jr., Reinecke, M. G., Abdel.Malek, S., Jia, Q., Chow, S. A. Inhibitors of HIV-1 replication that inhibit enzyme activity. Proc. Natl. Acad. Sci. U.S.A., 93, 6326-6331, 1996.

[39]. Matsuse, T. M., Nakabayashi, T., Lim, Y. A., Hussein, G. M. E., Miyashiro, H., Kakiuchi, N., Hattori, M., Stardjo, S., Shimotohno, K. A human immunodeficiency virus protease inhibitory substance from Swietenia mahagoni. Phytother. Res., 11, 433-436, 1997.

[40]. Ma, C-M., Kully, M., Khan, J.K., Hattori, M., Daneshtalab, M. Synthesis of chlorogenic acid derivatives with promising antifungal activity. Bioorg. Med. Chem., 15, 6830-6833, 2007.

[41]. Klein, L. L., Li, L., Chen, H. J., Curty, C. B., DeGoey, D. A., Grampovnik, D. J., Leone, C., L ., Thomas, S. A., Yeung, C. M., Funk, K. W., Kishore, V., Lundell, E. O., Wodka, D., Meulbroek, J. A., Alder, J. D., Nilius, A. M., Lartey, P. A., Plattner, J. J. Total Synthesis and 
Antifungal Evaluation of Cyclic Aminohexapeptides. Bioorg. Med. Chem., 8, 1677-1696, 2000.

[42]. Mclaughlin, J. L. In Ed. K. Hostettmann (ed). Methods in Plant Biochemistry, Academic Press, London, Vol. 6, p. 1-32, 1991.

[43]. Little,II, R.G., Lin, J-J., Gikonyo, J.G.K., US 6,355, 616 B1, 2002. 